\title{
PULMONARY BIPARTITIONING AND LOBAR TRANSPLANTATION: A NEW APPROACH TO DONOR ORGAN SHORTAGE
}

Jean-Paul A. Couetil, MD ${ }^{a}$

Michael J. Tolan, FRCSI ${ }^{\mathrm{a}}$

Didier F. Loulmet, MD ${ }^{a}$

Alain Guinvarch, $\mathrm{MD}^{\mathrm{a}}$

Patrick G. Chevalier, MD

Antoine Achkar, $\mathrm{MD}^{\mathrm{b}}$

Peter Birmbaum, MD ${ }^{\mathrm{a}}$

Alain F. Carpentier, MD, $\mathrm{PhD}^{\mathrm{a}}$
The scarcity of small donors has significantly limited lung transplantation for pediatric and small adult patients. Use of single lobes procured from sizeunmatched donors has overcome this difficulty, but only in a few selected cases and, in addition, it represents a waste of lung tissue. In an animal model we have shown that it is possible to divide one lung with careful partitioning of the vascular and bronchial structures and thus obtain two viable lobar grafts suitable for bilateral implantation in a smaller animal. We have now applied this procedure clinically in seven patients operated on between May 1993 and November 1994. The indications were cystic fibrosis in three children, primary pulmonary hypertension in two adults, bronchiectasis in one, and idiopathic pulmonary fibrosis in one. There were three children aged 13 to 17 years (median 14) and four adults aged 40 to 53 years (median 45). There was a $46 \%$ to $50 \%$ discrepancy for weight between recipient and donor and a $12 \%$ to $17 \%$ discrepancy for height. The surgical technique consisted of careful partitioning of the left donor lung, bilateral anterior thoracotomy in the recipient, and, with the use of cardiopulmonary bypass, implantation of the lower lobe in the left hemithorax and the upper lobe in the right hemithorax. Vascular and bronchial connections were facilitated by leaving a long pedicle on the recipient side. The pulmonary artery anastomosis for the donor left upper lobe was done with the "fissure" side of the artery to ensure an anastomosis without tension. An end-to-end bronchial anastomosis overcame the problem of size discrepancy. Six patients are alive and well 10 to 27 months (median 19) after operation. One patient with cystic fibrosis died of systemic aspergillosis infection. All were discharged from the hospital within the first or second postoperative month. No technical problems were identified: repeated bronchoscopy has demonstrated satisfactory healing without early stricture formation. All patients remain well subjectively with good exercise tolerance and all patients achieve greater than $70 \%$ of predicted values of forced expiratory volume in 1 second. Perfect adaptation of the transplanted lobes to the recipient pleural space has been demonstrated by postoperative computed tomographic scan. In conclusion, bilateral lobar transplantation from a single donor lung is possible in small adults or children when there is a large size discrepancy with the donor. This may help resolve the problem of donor availability in the pediatric population. (J Thorac Cardiovac Surg 1997;113: 529-37)
From the Department of Cardiothoracic Surgery, ${ }^{a}$ Broussais Hospital, Paris, and the Hôtel Dieu Hospital, ${ }^{b}$ Paris, France.

Read at the Seventy-fourth Annual Meeting of The American Association for Thoracic Surgery, New York, N.Y., April 24-27, 1994.

Received for publication Dec. 22, 1995; revisions requested March 28, 1996; revisions received Sept. 4, 1996; accepted for publication Sept. 24, 1996.

Address for reprints: Jean-Paul A. Couetil, MD, Department of Cardiovascular Surgery, Broussais Hospital, 96, Rue Didot, 75014 Paris, France.
Dulmonary transplantation for the pediatric population or for patients of small size is particularly limited by the now well-described scarcity of organs available for transplantation. ${ }^{1,2}$ Limitations of size mismatch and shortage of suitable donors make these groups of recipients especially difficult to accommodate. To circumvent these obstacles we

Copyright (C 1997 by Mosby-Year Book, Inc.

$0022-5223 / 97 \$ 5.00+0 \quad \mathbf{1 2 / 1 / 7 8 1 7 4}$ 
Table I. Donor/recipient size mismatch

\begin{tabular}{ccc}
\hline & Height $(\mathrm{cm})$ & TLC:LLC $(L)^{*}$ \\
\hline Adult recipients & & \\
R1:D1 & $150: 180$ & $4.10: 3.26$ \\
R2:D2 & $158: 190$ & $5.57: 3.06$ \\
R3:D3 & $163: 180$ & $5.10: 3.26$ \\
R4:D4 & $160: 188$ & $5.40: 3.46$ \\
Pediatric recipients & & \\
R5:D5 & $154: 174$ & $4.01: 3.04$ \\
R6:D6 & $140: 178$ & $3.06: 3.26$ \\
R7:D7 & $135: 170$ & $2.76: 2.42$ \\
\hline
\end{tabular}

$T L C$, Total lung capacity; $L L C$, estimated left lung capacity of donor (as $45 \%$ of predicted TLC of the donor); $R$, recipient; $D$, donor.

*Predicted values (predicted TLC has been calculated with the European Community for Coál and Steel Formula)

we have developed a technique of lung transplantation inspired by previous experience with liver bipartitioning.

Bismuth and Houssin ${ }^{3}$ have shown that splitting the liver into its constituent lobes allows two children to receive transplants from one liver. Recent studies of transplantation of pulmonary lobes in animals have been successful at medium-term follow-up with respect to hemodynamics and equitation of volume and conformity of the lobes in the thorax of the recipient. ${ }^{4-8}$ Satisfactory results of pulmonary reduction and lobar transplantation and liver bipartition, from either cadaveric ${ }^{9,10}$ or living donors, ${ }^{11-13}$ are reported clinically. We postulated that bipartitioning of one large donor lung into its constituent lobes would allow bilateral pulmonary transplantation into a recipient with a smaller thorax size.

We first showed the feasibility of the procedure experimentally. ${ }^{14}$ With adult dogs used as donors, either right or left single lungs were divided into separate lobes, which were subsequently implanted unilaterally and bilaterally into young dogs. Follow-up of up to 21 weeks demonstrated satisfactory bronchial and vascular anastomoses and perfect adaptation of the transplanted lobes to the morphology of the recipient thorax. After the success of these animal experiments the procedure was applied clinically for the first time in May 1993.

\section{Material and methods}

Between May 1993 and November 1994 seven bilateral lobar transplantations with a bipartitioned left donor lung were done at Broussais Hospital. There were five female and two male recipients. There were three children aged 13 to 17 years (median 14) and four adults aged 40 to 53 years (median 45). The cause of the end-stage lung disease was cystic fibrosis in the case of the three children; two adults had primary pulmonary hypertension with a mean pulmonary pressure of $85 \mathrm{~mm} \mathrm{Hg}$, one had infected bronchiectasis with a forced expiratory volume in 1 second $\left(\mathrm{FEV}_{1}\right)$ of $18 \%$, and one had idiopathic pulmonary fibrosis that confined him to a wheelchair. All patients required continuous $\mathrm{O}_{2}$ therapy and had grade IV dyspnea. Preoperative lung function tests in patients with cystic fibrosis revealed mean $\mathrm{FEV}_{1}$ values of less than $25 \%$ of predicted and forced vital capacity values less than $30 \%$ of predicted. All were judged to have a life expectancy of less than 12 months. Clinical application of the split lung technique was approved by our institutional review board and informed consent was obtained from each patient.

The criteria of suitability for a donor were similar to those of full-sized lung transplantation, except that bilateral lobe transplantation was done when there was a large discrepancy of height or weight between donor and recipient. In the present reported cases the weight discrepancy was $44 \%$ to $50 \%$ and the height discrepancy was $12 \%$ to $17 \%$ (Table I). The criteria of feasibility of the split lung technique with subsequent bilateral lobar transplantation were based on matching predicted donor left lung capacity estimated at $45 \%$ of the donor total lung capacity with the predicted recipient total lung capacity. A difference not exceeding $20 \%$ between donor left lung capacity and recipient total lung capacity is presently considered acceptable for transplantation.

\section{Surgical technique}

Donor operation. A median sternotomy is done and the pericardium and pleural cavities opened. The lungs are inspected and particular attention is paid to the left oblique fissure to ensure that it is well defined. In most young adult donors the fissure is well-defined and therefore does not present any difficulty in separation. The trachea, aorta, pulmonary artery, and both venae cavae are dissected free. Heparin is administered in a central venous line followed by prostacyclin (500 $\mu \mathrm{g}$ over 10 minutes) into the pulmonary artery. The heart is then excluded from the circulation by crossclamping the aorta and the venae cavae. Cardioplegic solution is administered via the ascending aorta and when the heart is arrested and the lungs still ventilated pneumoplegic solution is infused via the pulmonary artery (Papworth solution, $60 \mathrm{ml} / \mathrm{kg}$ ). The heart is decompressed by incising the inferior vena cava and the left atrial appendage. Topical cardiac and lung cooling is applied. The heart is then excised with care taken to leave enough atrial tissue surrounding the left and right pulmonary veins. After aspiration of bronchial secretions, the lungs are inflated, the endobronchial tube removed, and the trachea stapled and transected. The double lung block is then excised leaving the esophagus and the descending aorta in the donor chest. If the decision is made to transplant one lung in two different institutions (twinning procedure), the pulmonary block is divided on a secondary table in the operating room. The pericardium is split vertically midway between the two atrial cuffs and the pulmonary artery is divided at its bifurcation. The dissection is then completed at the level of the carina and the proximal left main bronchus is stapled and divided after the lungs are inflated. Each lung and heart is placed in a cold container for transportation. 


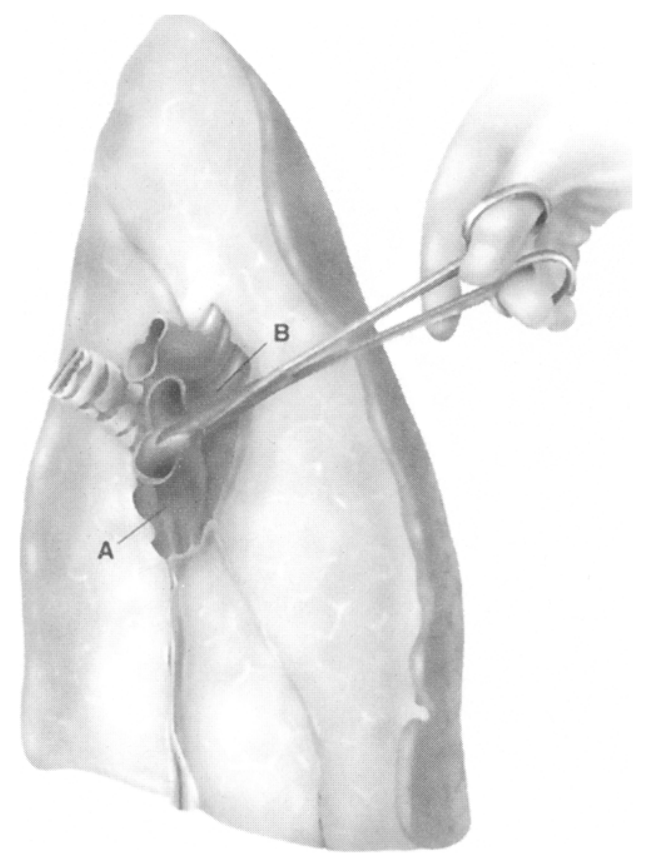

Fig. 1. View of the left lung showing the hilum with the bronchus posteriorly and the pulmonary artery anterosuperiorly. The confluence of the pulmonary veins anteroinferiorly is divided into inferior $(A)$ and superior $(B)$ veins.

Recipient operation. Anesthesia is induced in the patient and monitoring devices are placed, including a standard single-lumen tube, radial artery line, two central venous catheters, and a balloon-tipped catheter (SwanGanz catheter, Baxter Healthcare Corp.). Surgical exposure is via bilateral thoracotomy and transverse sternotomy through the fourth or fifth intercostal space (the "clamshell" incision). The pulmonary ligaments and any pleural adhesions are divided with cautery. The pulmonary artery is dissected intrapericardially and extrapericardially on both sides of the hilum and dissected as distally as possible into the parenchyma of the lung, beyond the upper lobe branch, to provide sufficient length for subsequent anastomosis. The inferior and superior pulmonary veins are dissected free and a tape passed around the superior pulmonary vein on the right.

Preparation of the donor lung. Bench preparation of the donor left lung involves separation of the upper and lower lobes, which may be completed within 15 minutes. Initial inspection determines the direction and completeness of the fissure and the presence of anatomic variants (Fig. 1). The oblique fissure is dissected down to the pulmonary artery. Small vessels that cross the fissure are clipped and divided. Parenchymal bridges are divided after stapling. After dissection of the fissure is completed the pulmonary artery is divided between the apical branch of the lower lobe and the lingular artery (Fig. 2). The two pulmonary veins are exposed on the mediastinal surface of the lung

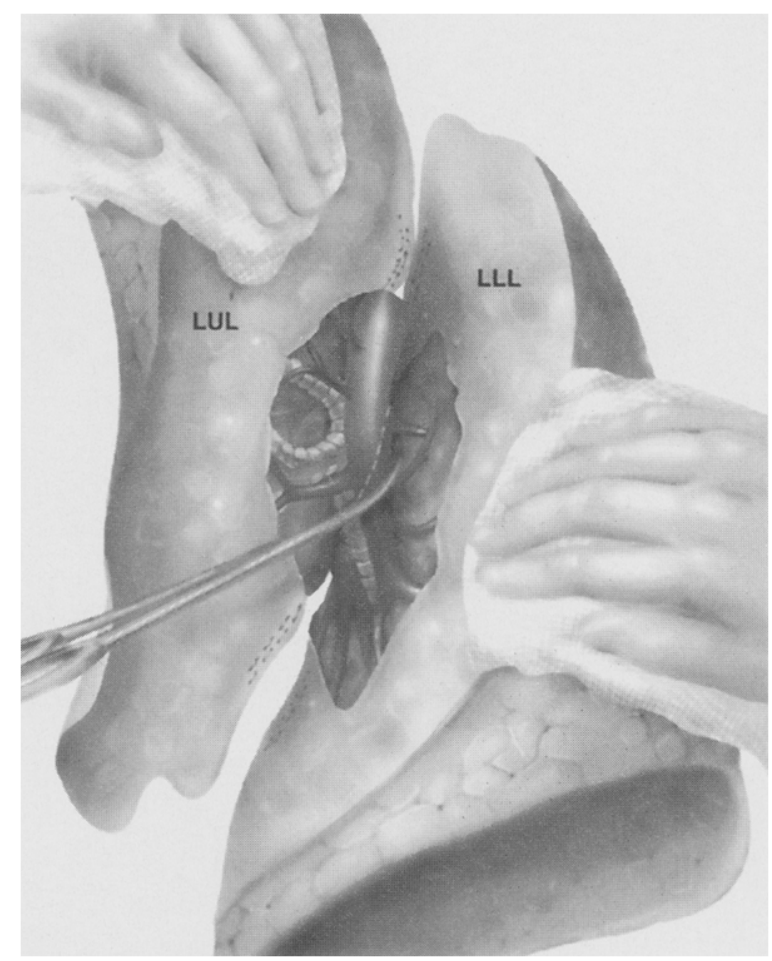

Fig. 2. After completion of dissection of the fissure, the pulmonary artery is divided between the apical branch of the lower lobe and the lingular artery (dotted line). LLL, Left lower lobe; LUL, left upper lobe.

and divided leaving a small cuff of atrial tissue. The two veins are separated from each other. The upper and lower lobe bronchi are dissected down to the level of the segmental branches with minimal dissection to preserve retrograde vascularization. Both upper and lower lobe bronchi are transected at their origin just before implantation of the donor lobes (Figs. 3 and 4).

Excision of the recipient right lung. Full normothermic cardiopulmonary bypass (CPB) with a beating heart is established between the ascending aorta and the right atrium with use of a two-stage venous cannula and ventilation is then stopped. The recipient right lung is then excised in a standard fashion, ${ }^{15}$ except that a vascular pedicle that is as long as possible is left (Fig. 5). The first branch of the pulmonary artery is ligated to achieve greater length. This is also useful for orientation of the anastomosis. The inferior vein is sutured closed in the adult, but in pediatric cases the recipient cuff is fashioned to incorporate both the inferior and superior veins.

Implantation of the left upper lobe in the right thorax. The donor left upper lobe is then placed in the right thorax, having been rotated 180 degrees along the vertical axis for approximation of donor and recipient hila (Fig. 4). Thus in this situation the posterior border of the donor left upper lobe becomes anterior and its anterior border lies posteriorly along the spine. This has the effect of placing the membranous portion of the donor bronchus opposite 


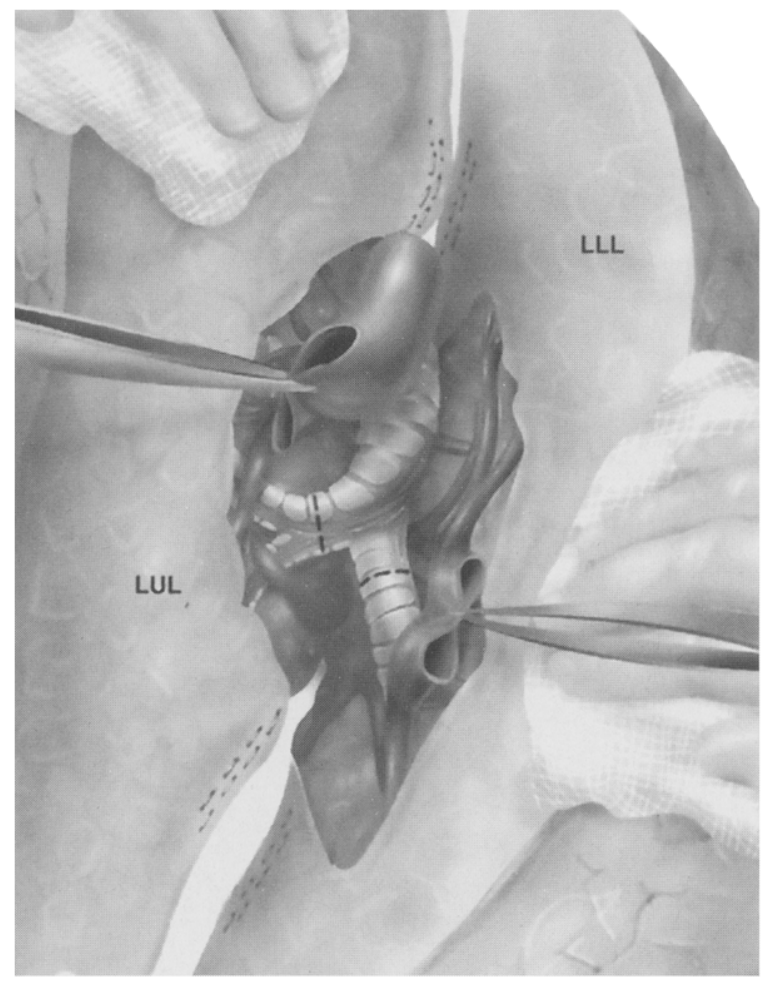

Fig. 3. The upper and lower lobe bronchi are dissected down to the level of the segmental branches and are transected at their origin (dotted lines). LLL, Left lower lobe; $L U L$, left upper lobe.

the cartilaginous portion of the recipient bronchus and vice versa. The donor pulmonary artery is posterosuperior to the donor bronchus and the recipient artery is anterior and slightly inferior to the recipient bronchus. The donor and recipient superior veins are well aligned. The bronchial anastomosis is done with continuous 4-0 polypropylene suture (Fig. 6). Any size mismatch is overcome by using an end-to-end anastomotic technique avoiding telescoping as far as is possible. The bronchi are sutured as they were aligned: cartilaginous portion of donor to membranous portion of recipient and vice versa (Figs. 6 and 7). Bronchial wrapping is not done.

Next, anastomosis of the donor pulmonary vein to the recipient superior pulmonary vein (continuous 5-0 polypropylene suture) is done. The proximal pulmonary artery of the donor is posterior to the bronchus but leads forward to the fissural section, which is anterior and in good alignment with the artery of the recipient. Therefore the proximal portion is trimmed to close to the upper segmental branches and oversewn, and the anastomosis is fashioned end-to-end with the recipient artery with 6-0 polypropylene suture (Fig. 8). The pulmonary artery anastomosis is made possible by previous dissection of sufficient length of the recipient artery to allow it to come forward in front of the bronchial anastomosis without tension or twisting.

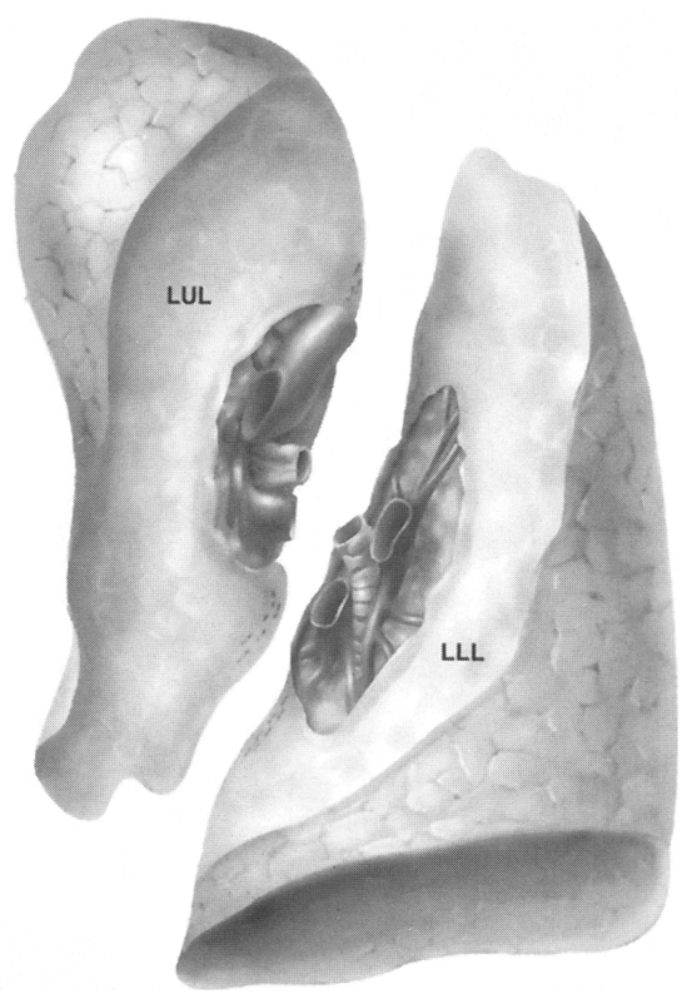

Fig. 4. The upper and lower lobes are aligned ready for implantation on the right and left sides, respectively. Note the fissural opening of the pulmonary artery anterosuperior to the bronchus. $L L L$, Left lower lobe; $L U L$, left upper lobe.

Retrograde deairing is achieved by release of the venous clamp and removal of air through the pulmonary artery before that anastomosis is secured. The right transplanted lobe is then ventilated gently with $50 \%$ inspired oxygen fraction. CPB is reduced to allow perfusion of the lobe.

Excision of the left lung. The recipient left lung is resected in a standard manner, but, again, a long vascular pedicle is left. The endotracheal tube is placed into the right main bronchus, and this procedure can be directly assisted by the surgeon. This ensures continued ventilation of the transplanted lobe.

Implantation of the left lower lobe in the left thorax. The donor left lower lobe is placed in the anatomic position in the thorax of the recipient. Alignment of the bronchi and vessels is uncomplicated (Fig. 9). Anastomoses are fashioned in the same order as done on the right side: bronchi followed by vein followed by artery. The bronchial anastomosis involves the main recipient bronchus. Again, any size mismatch is overcome while suturing the bronchi end-to-end. The venous anastomosis differs slightly from the right in that the recipient cuff is fashioned to incorporate both the superior and inferior veins because they are more closely aligned than on the right. Both recipient and donor arteries present anteri- 


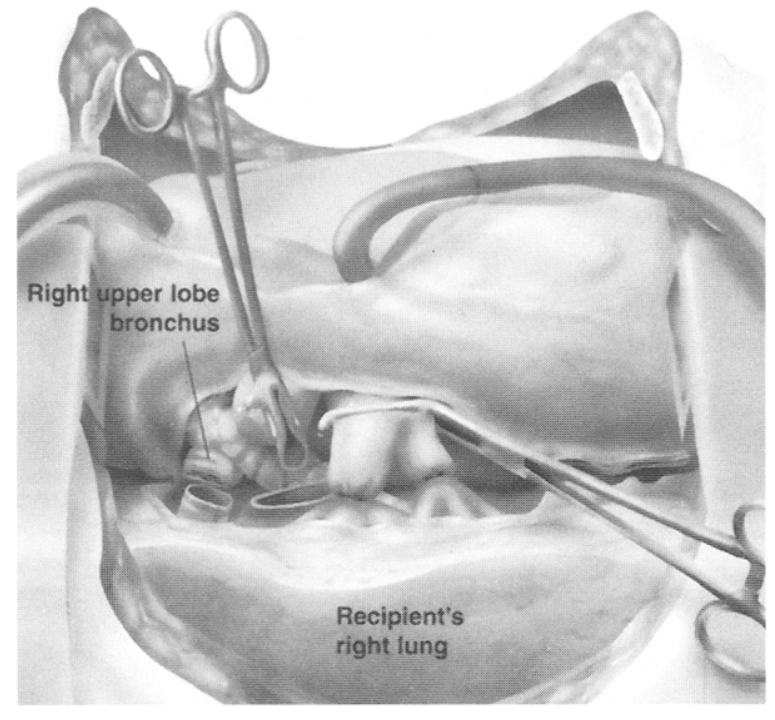

Fig. 5. Excision of the recipient right lung showing intrapericardial and extrapericardial dissection of the pulmonary artery to allow as long a pedicle as possible. (Note that the right upper lobe bronchus has been stapled.)

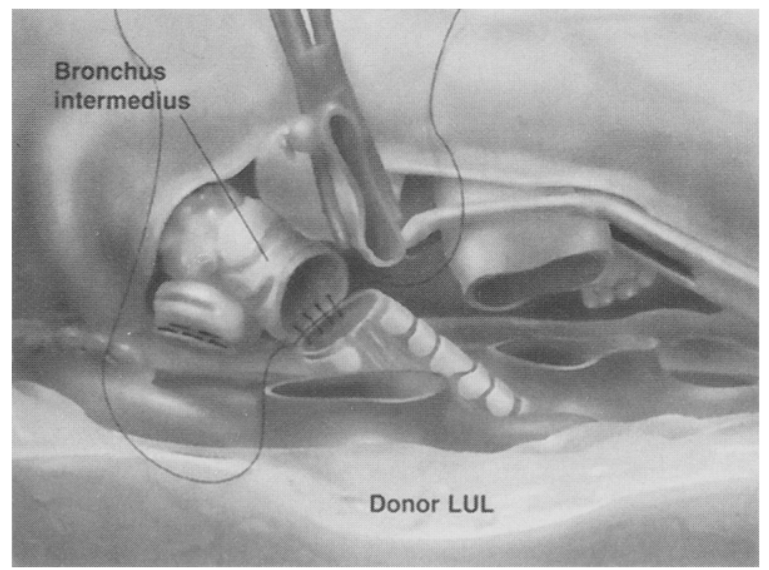

Fig. 6. Alignment of the donor left upper lobe ( $L U L)$ with the recipient right hilum. The end-to-end bronchial anastomosis is begun and is followed by the well-aligned pulmonary venous anastomosis.

orly and there are no special difficulties forming the anastomosis. Deairing procedures are repeated before the vascular anastomoses are secured. CPB is gradually discontinued.

At this stage in insertion of the left lower lobe, it may be apparent in some cases that the right graft in its new position is too long for the thorax. In such situations the lingula may be resected with a linear stapler.

Thereafter, bilateral drains are placed and the thoracotomy closed in layers.

Postoperative management. In the early phase management was aimed toward maintenance of optimum

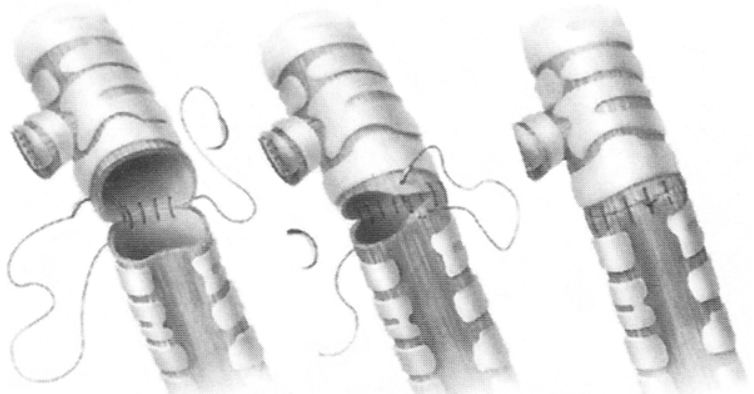

Fig. 7. The technique of bronchial anastomosis: a continuous end-to-end stitch sutures cartilaginous portion to membranous portion and vice versa.

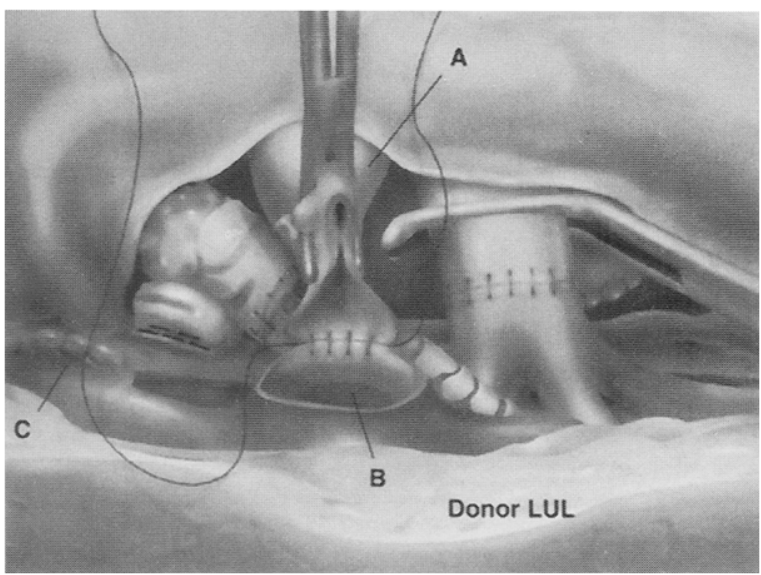

Fig. 8. The long pulmonary artery pedicle of the recipient $(A)$ is aligned with the fissural aspect of the donor pulmonary artery $(B)$ to form the anastomosis in front of the bronchial anastomosis $(C)$. $L U L$, Left upper lobe.

hemodynamics with restriction of fluid intake to avoid pulmonary edema and to allow early extubation. Patients were extubated as soon as oxygenation was adequate. Immunosuppression was based on a triple-drug therapy for isolated lung transplantation and included azathioprine, 2 to $3 \mathrm{mg} / \mathrm{kg}$, together with three doses of equine antithymocyte globulin and methyl prednisolone (1 gm at operation and $125 \mathrm{mg}$ three times daily for the first 24 hours). Steroids were then withheld for 8 days and resumed at a dosage of $1 \mathrm{mg} / \mathrm{kg}$ per day tapering to 0.2 $\mathrm{mg} / \mathrm{kg}$ per day by 6 months. Cyclosporine was given intravenously (1 to $2.5 \mathrm{mg} / \mathrm{kg}$ per day) for 8 days (doses were adjusted according to renal function and cyclosporine blood concentration). Oral cyclosporine administration was then started to maintain a serum level of 150 to $250 \mathrm{mg} / \mathrm{ml}$. Episodes of acute lung rejection were treated with bolus intravenous methylprednisolone $(15 \mathrm{mg} / \mathrm{kg}$ for 3 days) for grade 1 or 2 rejection. ${ }^{16,17}$ Antithymocyte globulin was added for persistent grade 1 to 2 or for grade 3 rejection. Diagnosis of rejection was made on clinical 


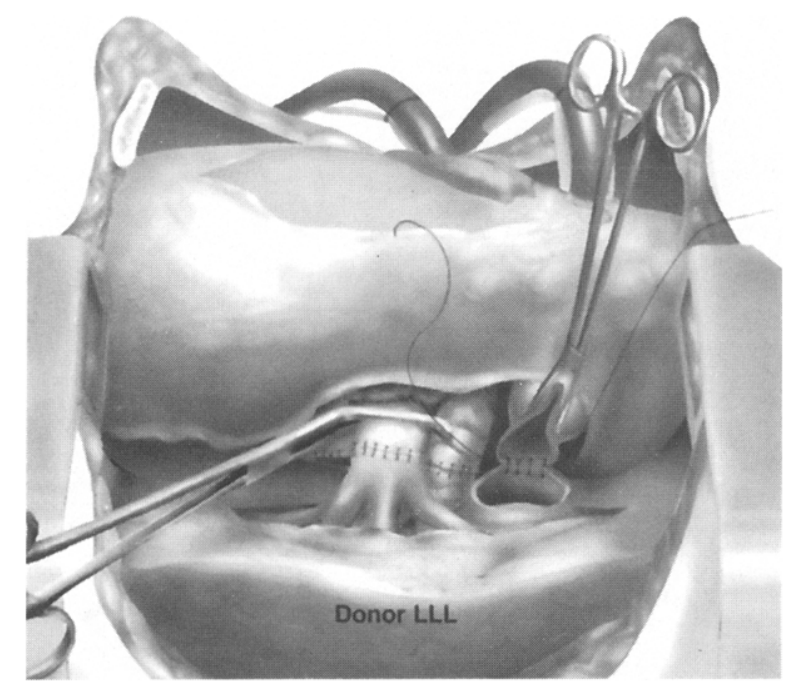

Fig. 9. The donor left lower lobe (LLL) implantation showing the completed bronchial and pulmonary venous anastomoses and the pulmonary artery anastomosis in progress. (Note that the recipient superior pulmonary vein is sutured to the donor lobar vein and the recipient inferior vein is sutured closed.)

grounds in the first 2 postoperative weeks and thereafter on the basis of transbronchial biopsy results.

Bronchoscopy, transbronchial biopsy, and lavage were done on a routine basis and when clinically indicated in the investigation of abnormalities on chest x-ray films, altered gas exchange, or unexplained fever. After discharge from the hospital patients were enrolled in a physiotherapy and rehabilitative program.

\section{Results}

Early results. There were no technical failures at the time of operation and all patients were successfully weaned from bypass. The graft ischemic time was 150 minutes for the first lobe (range 90 to 172) and 210 minutes for the second lobe (range 145 to 305). Additional procedures done included patent ductus arteriosus division and ligation, patent foramen ovale closure, and a reduced liver transplantation in a patient with cystic fibrosis. The duration of ventilation after operation ranged from 12 to 105 hours (median 30). There was one early death in a patient with cystic fibrosis in whom widespread systemic aspergillosis could not be controlled and who died of cerebral hemorrhage on day 21 after the operation. Morbidity was minimal. There were no bleeding complications, and neither bronchial stenosis nor dehiscence became apparent. There was a persistent air leak in two patients and three

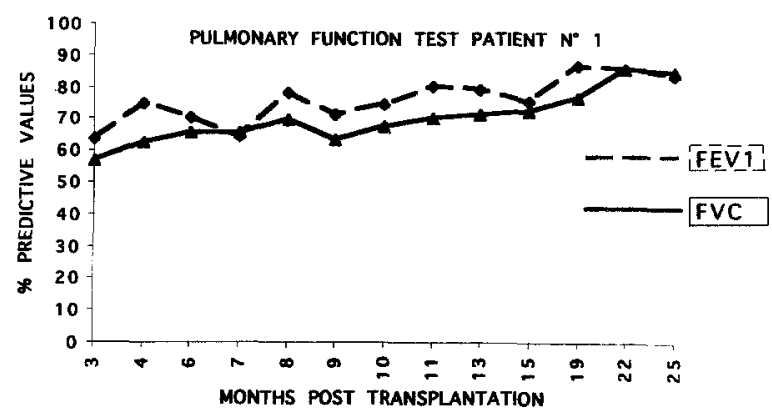

Fig. 10. Follow-up pulmonary function test results in our first patient during a 2-year postoperative period. FVC, Forced vital capacity.

others were noted to have partial pneumothoraces. Hospital stay ranged from 21 to 70 days (median 42).

Late results. Follow-up of the six survivors now ranges from 10 to 27 months (median 19). All patients are subjectively well with no major morbidity and minimal problems of rejection and infection. Median postoperative values of respiratory function tests are $\mathrm{FEV}_{1}, 1.83 \mathrm{~L} / \mathrm{min}(81 \%$ of predicted), and forced vital capacity, $2.53 \mathrm{~L}$ ( $71 \%$ of predicted). Percentages of predicted normal values for the recipients demonstrate an improvement with time after transplantation (Fig. 10). There has been only one case of bronchial stenosis, which was successfully treated by dilation. This occurred on the left side. Bronchoscopy in all other patients has demonstrated patent lumina that are free from ulceration and stricture. Follow-up computed tomographic (CT) scans have demonstrated disappearance of residual pneumothoraces and perfect adaptation of the transplanted lobes to the shape of the recipient thorax (Fig. 11). Of note in the majority of CT scans is a mild shift of the mediastinum toward the right probably caused by the longitudinal orientation of the transplanted lobe on the right (Fig. 12). The rightward shift of the mediastinum has never resulted in a perfusion/ventilation imbalance in any patient.

\section{Discussion}

Pulmonary transplantation faces the immense problem of lack of donors and increasing numbers of patients who require transplantation. The scarcity of organs has considerably limited the number of operations done. This is especially so in the case of children and adults of small size. The use of bilateral 


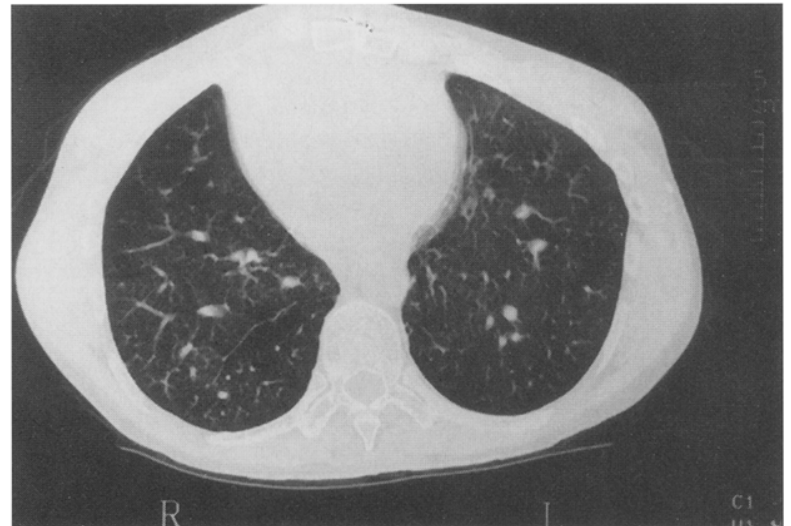

Fig. 11. Chest CT scan after bilateral lobar transplantation from split left lung. Note the good adaptation of the transplanted lobe to the shape of the recipient thorax and the mild shift of the mediastinum to the right.

lung replacement for cystic fibrosis as advocated by the Toronto Lung Transplant Group since 1988 places further demands on the donor pool. With the hope of expanding the possibilities for transplantation, techniques of pulmonary reduction and lobar transplantation, from either live or cadaveric donors, have been developed. ${ }^{9,11,12}$ These techniques, although they increase pediatric transplantation still lead to some wastage of organs with loss of one or several nontransplanted lobes. Partitioning of the lung is one approach that resolves the discrepancy in size between donor and recipient and maximizes use of available organs. This technique has been used with success in liver transplantation and allows two children to receive transplants from one liver. ${ }^{18}$ With use of the techniques described in this paper, it is now also possible that one large donor lung can be separated into two lobes and implanted bilaterally in a child and the second donor lung may be used in a second recipient.

We have previously described our experiments in a dog model in which we separated the lobes of the right or left lung of an adult dog and implanted them bilaterally in young dogs. ${ }^{14}$ The success of these experiments has now resulted in our performing the first seven clinical cases. Several technical points require elaboration. In the recipient it is essential that sufficient lengths of vascular and bronchial pedicles are retained to avoid any anastomotic tension. Care must be taken in positioning the donor lobe in the thorax before the vessels are anastomosed to ensure that there is no undue tension when ventilation is

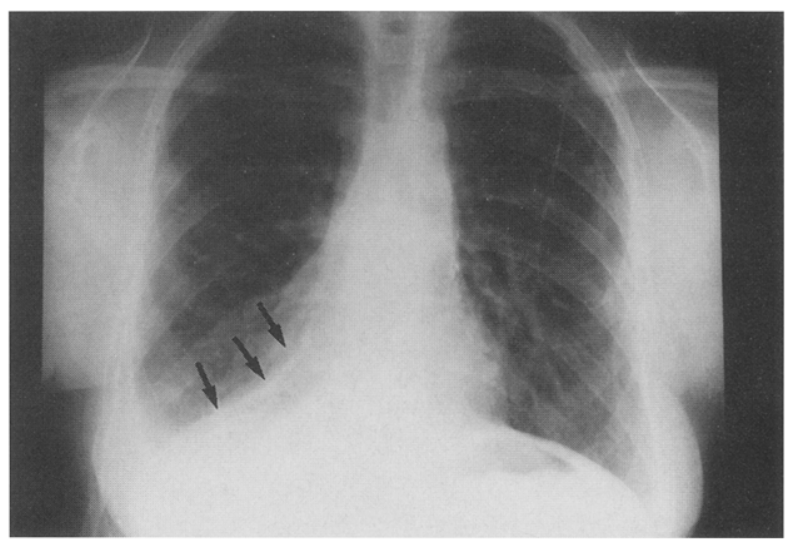

Fig. 12. Postoperative chest radiograph showing rightward shift of the mediastinum. Arrows show the section line of the resected lingula.

restored. In one case in the experimental series the malposition of a lobe caused twisting of an arterial suture line and massive infarction of the lobe.

The quality of bronchial healing both in the experimental animal series and in this clinical series was remarkably good. An end-to-end bronchial anastomotic technique was necessary because of inequality of diameters and therefore a certain amount of telescoping invariably occurred. When a lobe was transplanted on the contralateral side the rotation of the bronchus necessitated anastomosis of the muscularis portion to the cartilaginous ring portion and vice versa (Fig. 7). This did not cause any delay in healing and perhaps the presence of cartilage circumferentially actually helps to splint the anastomosis open.

After preparation of the donor left upper lobe it may be noted that there are two open orifices of the pulmonary artery. One opening is the place where it has been separated from the main pulmonary artery at the hilum, and the other is where the lower lobe artery has been separated from it in the fissure. A most important and not obvious technical point is that the second of these orifices, that is, the fissural opening, is used for anastomosis to the recipient pulmonary artery; the proximal opening of the main pulmonary artery is closed with a continuous suture after it is tailored back to the first branches. This technical consideration simplifies the whole procedure, avoids any twist in the pulmonary artery, and creates a smooth, wellaligned end-to-end anastomosis that is hypobron- 
chial. An anastomosis that used the proximal pulmonary artery orifice would be an epibronchial anastomosis, which would be prone to tension and torsion over the bronchus.

It is our policy to use CPB inasmuch as there are several advantages in the pediatric population with cystic fibrosis: double-lumen endotracheal intubation is not required, bronchial toilet with antibiotic solutions in patients with cystic fibrosis is possible, spread of purulent secretions is prevented, exposure to the hilum is improved in the presence of deflated lungs, and, perhaps most important, the use of CPB allows an expeditious pneumonectomy and decreases the implantation time for the second graft. However, in small adults sequential lobar implantation can be done without CPB.

It is our policy to perform single-lung transplantation in patients with idiopathic pulmonary fibrosis. Nevertheless, because our patient with idiopathic pulmonary fibrosis was critically ill and in clinically failing condition and because we could not find a size-matched donor, we were concerned that transplantation of only one lobe would have not provided enough pulmonary parenchyma to sustain a normal life and this patient was afforded bilateral lobar transplantation.

There are several remaining incompletely resolved issues pertaining to lobar transplantation. A potential problem is the physiologic adaptation of a mature lobe in the growing thorax of a child. Preliminary animal results suggest that the number of functional alveoli does not grow but a distension of existing alveoli parallels the growth of the chest. $^{19,20}$ Thus the increase in the size of a mature lobe is a result of alveolar distension and compensatory functional size does not increase. This may be a limiting factor in applying the technique clinically, but if the dilation of air spaces is proportional to the growth of microvasculature the functional capabilities of the alveolus may be preserved. A further problem may be that of effects on pulmonary vascular resistance, ${ }^{21}$ which remain unknown and may vary in different clinical situations. We have not encountered any episodes of elevated pulmonary artery pressure to date.

In conclusion, after the success of our animal experiments we have now shown that the technique of lobar separation of the left lung followed by bilateral transplantation is feasible and easily done without an increase in mortality or morbidity. Carefully selected patients with a large size discrepancy with the donor demonstrate good functional results.
After hospital discharge patients have returned to a normal life-style with adequate arterial gaseous exchange on exertion. There has been full adaptation of the lobes to the shape of the recipient thorax. Further long-term studies in animals and clinical results are awaited to assess the full potential of this technique in increasing the number of transplantations in children and adults of short stature. We are at present developing a technique of separation of lobes of the right lung and their subsequent transplantation.

\section{REFERENCES}

1. Couetil JP, Scott JP, Serrano-Fiz S, Higenbottam TW, Wallwork J. Transplantation cardiopulmonaire: experience de Cambridge. Coeur 1989;20:9-13.

2. Spray TL, Mallory GB, Cantter Cb, Huddleston CB. Pediatric lung transplantation: indications, techniques, and early results. J Thorac Cardiovasc Surg 1994;107:990-1000.

3. Bismuth $H$, Houssin D. Reduced size orthoptic liver grafts in hepatic transplantation in children. Surgery 1984;95: 367-70.

4. Lillehei CW, Everts E, Shamberger RC. Reduced size lung transplantation from adult to neonatal sheep. J Pediatr Surg 1992;27:1153-6.

5. Cromblehome TM, Adzick NS, Longaker MT. Reduced size lung transplantation in neonatal swine: technique and short term physiologic response. Ann Thorac Surg 1990;49:55-60.

6. Haverich A, Dammenhayn L, Demertzis S, Kemnitz J, Reimers P. Lung growth after experimental pulmonary transplantation. J Heart Lung Transplant 1991;10:288-95.

7. Hislop AA, Odom NJ, McGregor CG, Haworth SG. Growth potential of the immature transplanted lung: an experimental study. J Thorac Cardiovasc Surg 1990;100:360-70.

8. Huggins E. Reimplantation of lobes of the lung: an experimental technique. Lancet 1959;2:1059-61.

9. Otte JB, de Ville de Goyet J, Sokal E, et al. Size reduction of the donor liver is a safe way to alleviate the shortage of size-matched organs in pediatric liver transplantation. Ann Surg 1990;211:146-57.

10. Starnes VA, Barr ML, Cohen RG. Lobar implantation: indications, techniques and outcome. J Thorac Cardiovase Surg 1994;108:403-11.

11. Strong RW, Lynch SW, Ong TH, Matsunami H, Koidy L, Balderson G. Successful liver transplantation from a living donor to her son. N Engl J Med 1990;322:1505-7.

12. Backer CL, Ohtake S, Zales VR. Living related lobar lung transplantation in beagle puppies. J Pediatr Surg 1991;26: 429-33.

13. Cohen RG, Barr ML, Schenkel FA, DeMeester TR, Wells WJ, Starnes VA. Living related donor lobectomy for bilateral lobar transplantation in patients with cystic fibrosis. Ann Thorac Surg 1994;57:1423-8.

14. Couetil JP, Grousset A, Tolan MJ, Benaim A, Fayolle P, Carpentier A. Experimental bilateral lobar lung transplantation and its application in the human. Thorax. In press.

15. Pasque MK, Cooper JD, Kaiser LR, Haydock DA, Triantafillou A, Trulock EP. Improved technique for bilateral lung transplantation: rationale and initial clinical experience. Ann Thorac Surg 1990;49:785-91. 
16. Yousem SA, Berry GJ, Brunt EM, et al. A working formulation for the standardization of nomenclature in the diagnosis of heart and lung rejection: lung rejection study group. J Heart Transplant 1990;9:593-601.

17. Cooper JD, Billingham M, Egan T, et al. A working formulation for the standardization of nomenclature and for clinical staging of chronic dysfunction in lung allografts. J Heart Lung Transplant 1993;12:713-6.

18. Otte JB, de Ville de Goyet J, de Hemptinne B, et al. The concept and technique of the split liver in clinical transplantation. Surgery 1990;107:605-12.
19. Kern JA, Tribble CG, Zografakis JG, Cassada DC, Chan BB, Kron IL. Analysis of airway function of immature whole lung transplants versus mature lobar transplants. Ann Thorac Surg 1994;57:1089-94.

20. Kern JA, Tribble CG, Flanagan TL, Chan BB, Cassada DC, Kron IL. Growth potential of porcine reduced-size mature pulmonary lobar transplants. J Thorac Cardiovasc Surg 1992; 104:1329-32.

21. Kern JA, Tribble CG, Chan BK, Flanagan TL, Kron TL. Reduced-size porcine lung transplantation: long-term studies of pulmonary resistance. Ann Thorac Surg 1992;53:583-9.

\section{Bound volumes available to subscribers}

Bound volumes of The Journal of Thoracic and Cardiovascular Surgery are available to subscribers (only) for the 1997 issues from the Publisher, at a cost of $\$ 110.50$ for domestic, $\$ 139.64$ for Canadian, and $\$ 130.50$ for international subscribers for Vol. 113 (January-June) and Vol. 114 (July-December). Shipping charges are included. Each bound volume contains a subject and author index and all advertising is removed. Copies are shipped within 60 days after publication of the last issue of the volume. The binding is durable buckram with the Journal name, volume number, and year stamped in gold on the spine. Payment must accompany all orders. Contact Mosby-Year Book, Inc., Subscription Services, 11830 Westline Industrial Drive, St. Louis, Missouri 63146-3318, USA; phone 800-453-4351 or 314-453-4351.

Subscriptions must be in force to qualify. Bound volumes are not available in place of a regular Journal subscription. 